\title{
Pros and Cons of Using ICT in Teaching ESL Reading and Writing
}

\author{
Melor Md Yunus ${ }^{1}$, Norazah Nordin ${ }^{1}$, Hadi Salehi ${ }^{1,2}$, Choo Hui Sun ${ }^{1} \&$ Mohamed Amin Embi ${ }^{1}$ \\ ${ }^{1}$ Faculty of Education, Universiti Kebangsaan Malaysia (UKM), 43600 Bangi, Malaysia \\ ${ }^{2}$ Faculty of Literature and Humanities, Najafabad Branch, Islamic Azad University, Najafabad, Isfahan, Iran \\ Correspondence: Hadi Salehi, Faculty of Literature and Humanities, Najafabad Branch, Islamic Azad University, \\ Najafabad, Isfahan, Iran. Tel: 98-601-7653-8260. E-mail: hadisalehi1358@yahoo.com
}

Received: March 25, 2013 Accepted: April 17, 2013 Online Published: June 24, 2013

doi:10.5539/ies.v6n7p119 URL: http://dx.doi.org/10.5539/ies.v6n7p119

\begin{abstract}
Information and Communication Technologies (ICTs) play a major role in creating a new and improved model of teaching and learning. A great number of studies have been conducted to examine the advantages of integrating ICT in language education in general and English as a Second Language (ESL) teaching and learning in particular. However, there is a need for more studies on the disadvantages of using ICT in language education. This study aims to identify both advantages and disadvantages of using ICT in teaching ESL reading and writing. To achieve the aim of the study, a total of 23 secondary school English teachers were interviewed. The teachers were pragmatically and purposively selected from three different areas of Malaysia, 7 teachers from Alor Setar, 8 teachers from Tawau and 8 teachers from Johor Bahru, respectively. This study is a qualitative research in nature because a semi-structured interview was used to examine the teachers' perceptions of pros and cons of using ICT in teaching ESL reading and writing. The findings of the study revealed that attracting students' attention, facilitating students' learning process, helping to improve students' vocabulary knowledge and promoting meaningful learning were regarded as the most important advantages of using ICT in teaching ESL reading and writing. Moreover, disadvantages found included the difficulty in classroom control and students' distraction as well as their tendency to use short forms in writing tasks. The findings of the study are hoped to provide the teachers and policymakers with a better and more accurate picture of advantages and disadvantages of using ICT tools in ESL teaching and learning contexts.
\end{abstract}

Keywords: Information and Communication Technology (ICT), English as a Second Language (ESL), reading, writing, pros and cons, teaching, learning

\section{Introduction}

Information and communication technologies (ICTs) cover a wide range of technologies. ICTs refer to technological tools and resources which are employed to communicate, create, disseminate and manage information (Thierer, 2001; Nordin, Embi \& Yunus, 2009; Nordin et al., 2010). These technologies include radio, television, computers, Internet, social networks and etc. In the last decade, there has been a growing interest in using computers and the internet to improve the effectiveness of teaching and learning in all levels and in both educational and non-educational settings. Although nowadays the older technologies such as radio, television and telephone are given less attention, they have a longer and richer background as educational tools. Therefore, the integration of new ICT tools such as laptop, interactive whiteboard, LCD projector, Internet and social networks in education is still in its infancy in comparison with the use of older technologies such as radio and television (Salehi \& Salehi, 2011). This is due to the limited infrastructure of ICTs and the high costs of access to internet in developing countries (Carlson \& Firpo, 2001).

Since the implementation computer system in the 1960s, the Malaysian government has introduced various plans and measures to facilitate the greater integration of Information and Communications Technology (ICT) to improve capacities of every field, including education. These measures include the enhancement of education and training programmes, provision of an environment conducive to the development of ICT, and provision of incentives for computerization and automation (Melor Md Yunus, 2007).

The concept of ICT in education, as seen by the Ministry of Education, includes systems that enable information gathering, management, manipulation, access, and communication in various forms. The Ministry has formulated three main policies for ICT in education (Ministry of Education Malaysia, 2003). The first policy is that of ICT for 
all students, meaning that ICT is used as an enabler to reduce the digital gap between the schools. The second policy emphasizes the role and function of ICT in education as a teaching and learning tool, as part of a subject, and as a subject by itself. Apart from radio and television as a teaching and learning tool, this policy stresses the use of the computer for accessing information, communication, and as a productivity tool. The third policy emphasizes using ICT to increase productivity, efficiency and effectiveness of the management system. ICT will be extensively used to automate and mechanize work processes such as the processing of official forms, timetable generation, management of information systems, lesson planning, financial management, and the maintenance of inventories.

\section{Literature Review}

The use of ICT in English as a Second Language (ESL) teaching and learning is one of the most widely discussed issues in the field of education (Yunus \& Salehi, 2012). A group of ICT researchers claim that using ICT improves education and provides more teaching and learning supports for the teachers and learners (see Westera \& Sloep, 2001; Young, 2003; Salehi \& Salehi, 2012; Yunus, Salehi \& Chenzi, 2012). There is no doubt that using ICT in education improves teachers' instructional process and facilitates students' learning process. A great number of studies have shown the advantages of using ICT in ESL teaching and learning; however, there is a need for more studies on the disadvantages of using ICT in language education. The purpose of this study is to explore the pros and cons of integrating ICT tools in teaching ESL reading and writing.

Reading involves the process of decoding words (Floyd et al., 2007) whereas writing on the other hand, involves the reverse - encoding process. Both skills are important in the aspect of language learning. Although ICT could be an important tool to enhance the teaching of ESL reading and writing, there are pros and cons of using the tool. Thus, the following sub-sections discuss the pros and cons of using ICT in teaching reading and writing skills.

\subsection{Advantages of Using ICT}

One of the popular tools which is commonly adapted in the teaching of reading and writing is the use of blogs. Blogging offers a real-world digital medium for communication. It is multi-dimensional in that it does not just offer a 'container' for writing but has the possibility of multiple audiences and access points. In a research conducted on the effectiveness of using the 'online writing' approach in teaching writing, Kelly \& Safford (2009) drew upon data from a research project undertaken in 2 years from 6 classrooms during the 2006 World Cup, to analyze how children used complex sentence structures in their writing on a football web-log. They explore how the confluence of a temporary, popular, global event and an online forum for communication created a moment of linguistic empowerment where pupils began to use high-level forms of language. This research shows positive findings in terms of the students' interested in presenting ideas and responding to their classmates' ideas by commenting on the blog. Online blogs allow students to get feedback from more than one person, and this type of peer feedback may be more effective than traditional self-editing (Holder, 2006). It gives the implication towards the positive interactivity for the teaching and learning of sentence grammar, by using blogs in the teaching of writing.

The researchers also concluded that it is perhaps the dialogic nature of the blog that powered this language perhaps it was the blog's communicative network that enabled the children to hypothesize and defend their reasoning and speculation using complex sentence structures. Blogs are also popular forums for many teens to express themselves, and there is growing evidence that teens having their own blogs tend to be prolific writers inside and outside of school (Lenhart et al., 2008). Moreover, when students post their writing online, the audience transforms from one person (i.e., the teacher) to a larger social community. This changes the dynamic of writing from something that is done to receive a grade to place it in a social context where form, style, and understanding of audience take on increased importance (Sweeny, 2010).

Besides the use of blogs in the teaching of reading and writing, in 'Authoring With Video', Strassman \& O' Connell (2007) explored the advantages of using technology to motivate students to apply knowledge in any content area to a writing task. Authoring With Video (AWV) enables students to get started writing in a medium they know and love - video. It is similar to writing text for a wordless picture book. The videos, like the pictures in a wordless book, serve as the trigger for an organized text. Finding their voices as writers is less of a challenge for students because they are comfortable with messages and visual images working together to communicate meaning. AWV encourages students to formally recognize this ability as a skill that has its roots in writing. It capitalizes on the sophisticated video-viewing and comprehension abilities of learners and casts them as writers, publishers, and producers of content. Students would revise more and spend more time on task when they are engaged in a project that has an audience beyond their teacher. Students' motivation to fully engage in writing and revising text is sparked by their desire to communicate with the reader and by their individual pride of 
authorship. All of these factors can increase student engagement with written language and increase the quantity of writing produced. AWV also has the added incentive of producing completed movies to share with classmates, friends, and family. The finished product looks professional and can be easily posted to a website or blog.

Another advantage is seen from the use of e-learning or online education. Online education is defined as an approach to teaching and learning that utilizes new technology to communicate and collaborate in an educational context (Piezon \& Donaldson, 2005). The process of online communication enables the learners to actively construct their own perspectives which they can communicate to a small group. Learners engage in active, constructive, intentional, authentic and collaborative learning. Enabling the groups to socially construct knowledge through communicating and collaborating with others is an important element of constructivist-based online learning and teaching (Meyer, 2002 as cited in Aksal, 2009). In this context, ICT is seen to provide a platform for active and meaningful learning to occur.

A study was carried out by Blachowicz et al. (2009) to observe the technology in use by the students, to observe the classroom dynamics and teacher choices centred on the technology use, to look at student learning, and to learn about student and teacher perceptions and beliefs about technology. A computer-assisted literacy programme is designed to aid reading instruction in language classrooms. The findings suggested that students were motivated, on task, and attentive when working on their literacy tasks. The management and approach to the centres was more focused and required less teacher management than many other aspects of instructional time, freeing the teacher to focus on other issues. Besides, the learning technology allowed students to develop independent work habits and to build both their skills and confidence about literacy and about using technology. Both teachers and students commented on the fact that they saw skills, focus, attention, and confidence being built. Several teachers noted that students who did not exhibit much attentional control at the start of the year were able to attend at the technology centre and felt that the students then became more able to focus in class. Analyses of student performance also suggest that student performance improved in the classes in which the literacy technology was used (Blachowicz et al., 2009).

In another related study on the use of ICT in the teaching of reading specifically, Yuksel \& Tanriverdi (2009) explored the effects of watching captioned movie clip on vocabulary development of EFL learners. When the findings of this study are interpreted, it can be argued that viewing the movie clip has helped the participants of the study develop their vocabulary knowledge, and this would facilitate the reading process.

The advantages of using technology are also being addressed by Considine, Horton \& Moorman (2009) in terms of using different media resources for different instruction. Some of the media tried out include songs, editorial cartoons, video clips and internet resources to engage students in the learning process. Strategies for engaging students in media literacy activities are becoming more available as instructional frameworks or templates have been identified for analyzing different types of media. The emergence of ICT has shown to intensify the impact of media on culture and schooling. Connecting reading, writing, visual, and technological literacy provided students with opportunities to write for wider audiences and to produce authentic texts such as online book reviews (Lawrence, McNeal \& Yildiz, 2009).

Moving on to an integral part of ICT, which is the internet. With the amount of information up on the net, users are able to collaborate and broaden their experience. Students could take responsibility for finding answers to suit their own learning needs (Choi \& Ho, 2002 as cited in Sweeny, 2010). Another advantage is that it promotes collaborative learning. The Internet allows like-minded people to communicate through websites, blogs, and social networking sites. Many of these sites include an option that permits users to work collaboratively and publish their writing. This type of writing is becoming more prevalent in the workplace, so exposing students to this process may provide them with skills that will translate directly to their future work as adults.

Besides that, research in the use of Computer Assisted Language Learning (CALL) in the writing classroom has indicated that CALL creates a supportive and motivating environment for learners conducive to students to work at their own pace and linguistic developmental level and enhances their independent writing skills in terms of quality and quantity (Lam \& Pennington, 1995; Bialo \& Sivin-Kachala, 1996; Goldberg, Russell \& Cook 2003; Stepp-Greany, 2002 as cited in Fidaoui, Bahous, \& Bacha, 2010).

ICT supports the modern principles of learning and language acquisition. Individualisation, interaction and student motivation, often considered paramount in modern education theories, are necessarily a part of the process in ICT. Mullamaa (2010) discussed the relationship between student motivation and e-learning. It is suggested that a well-balanced ICT environment will enable students to feel the above and stay motivated throughout the learning process. Motivation, individualisation, learning in context and the activation of the learner - all buzzwords in modern education - are often a part and parcel of a successful ICT support. 


\subsection{Disadvantages of Using ICT}

Besides having the advantages, there are some disadvantages regarding the use of ICT in the teaching of reading and writing. Two concerns that teachers have about using technology such as Instant Messaging (IM) or blogs with their students is that students will not take the work seriously and will not use what they have learned in school in their postings (Sweeny, 2010). Moreover, as Ward (2004) pointed out, although students could be exposed to a variety of reading materials and genres of writing, there is a danger that the reading skills that are developed from scrolling the computer screen lead to an accelerated but superficial, and often inaccurate, understanding of the content.

To sum up, the advantages of using ICT in the teaching of reading and writing found in the literature include gaining students' interest in presenting their ideas and responding to their classmates' ideas, allowing effective peer feedback, giving positive interactivity within the teaching and learning, motivating students to apply knowledge in any content area to a writing task, engaging students in different projects, increasing student engagement with the language, allowing the utilization of new technology to communicate and collaborate in an educational context, providing a platform for active and meaningful learning to occur, developing independent work habits, improving learners' vocabulary knowledge, allowing user collaboration and the publishing of work such as writing. As for the disadvantages, the literature suggests that the use of computer technology could cause the lackadaisical attitude among students whereby they will not take their work seriously and that the students' reading skills developed from scrolling the computer screen could lead to an accelerated but superficial, inaccurate understanding of the content.

\section{Methodology}

This study is a qualitative research in nature. A total of 23 secondary school English teachers were interviewed. The teachers were pragmatically and purposively selected from three different areas of Malaysia, 7 teachers from Alor Setar, 8 teachers from Tawau and 8 teachers from Johor Bahru, respectively. In-depth interviews provide the researcher with a comprehensive view of what the participants perceive. The purpose of employing a qualitative method for this study is to obtain comprehensive opinions of the respondents to what they feel about the pros and cons of using ICT in their instruction. Results from such interviews often yield quantifiable descriptions which can be used in further statistical analysis aimed at identifying effective use of ICT in teaching reading and writing skills in ESL classrooms.

The instrument used for this research was a semi-structured interview. The questions of the interview were structured to find the answer for the following research question:

What are the advantages and disadvantages of using ICT in teaching reading and writing skills in ESL classrooms?

The objective of designing interviews in this study was to obtain in-depth and detailed information about the participants' perceptions and attitudes towards the advantages and disadvantages of using ICT in teaching ESL reading and writing. The interview questions were developed by the researchers and initial modifications were made in order to tailor the questions to reflect the nature of the research question. In the development process of the interview questions, in order to ensure the content validity, first of all, the present researchers reviewed the relevant literature and examined the interview protocols designed for similar purposes. The first draft of the interview questions were developed considering the issues pointed in the literature. Then, the content validity and face validity of the interview protocol were checked by a panel of experts. The experts' comments and suggestions were implemented to develop the second draft of the protocol. To ensure the reliability of the interview questions, the second drafts were piloted on 3 English teachers. The piloting of the second drafts of the interviews showed that all the questions were clear and the interviewees were not encountered with any problems due to the wording of the questions.

The necessary permissions were obtained from both the school principals and the teachers. Moreover, the consent forms were read and signed by all the participants before conducting the interviews. All the interviews were conducted in English in September 2012. The interviews lasted for about 30 to 45 minutes. The interviews were audio-recorded. After conducting the interviews, the recorded interviews were transcribed verbatim. They were also organized, coded and analyzed. In order to analyze the interview data, several steps have been conducted. Right after each interview session, the researcher transcribed the recorded interviews and referred to his notes on what he has jotted down as the interview went along to avoid losing any important data which might become significant to the findings of this research. The researcher then contacted the research interviewees to confirm the accuracy of the transcriptions and notes as interpreted by the researcher. All participants were given a pseudonym for the purpose of anonymity. 


\section{Results and Discussion}

\subsection{Participants' Demographic Information}

Table 4.1 summarizes the details of the interviewed teachers. As it can be seen in the below table, twenty-three secondary school English teachers were selected from three different areas of Malaysia, 7 teachers from Alor Setar, 8 teachers from Tawau, and 8 teachers from Johor Bahru, respectively. Eighteen interviewees were female and five interviewees were male. The below table clearly illustrates that only five teachers aged 20 to 30 and the remaining 18 teachers aged over 30 indicating that the majority of the interviewed English teachers were middle-aged. Most of the teachers had at least 5 years of teaching experience.

Table 4.1. Basic Information about Interviewed teachers

\begin{tabular}{lllll}
\hline Area & Name & Gender & Age & Teaching experience (year) \\
\hline Alor Setar & Lai & F & 53 & 27 \\
& Norlina & F & 42 & 18 \\
& Fadhil & M & 53 & 30 \\
& Siti & F & 42 & 18 \\
& Sarah & F & 37 & 10 \\
Tawau & Hasnah & F & 55 & 34 \\
& Zalilah & F & 45 & 18 \\
& Ida & F & 32 & 9 \\
& Cindy & F & 24 & 1 \\
& Aliff & M & 31 & 7 \\
& Najeeb & M & 42 & 22 \\
& Harith & M & 25 & 1 \\
& Hamzah & M & 34 & 11 \\
& Nisa & F & 29 & 4 \\
& Nabihah & F & 28 & 4 \\
Johor Bahru & Aini & F & 40 & 15 \\
& Badariah & F & 38 & 15 \\
Chin & F & 43 & 16 \\
& Diyana & F & 26 & 2 \\
Erma & F & 33 & 7 \\
& Fetty & F & 35 & 7 \\
Goh & F & 40 & 15 \\
& Huda & F & 35 & 6 \\
\hline \multirow{5}{*}{} & & & &
\end{tabular}

\subsection{Main Findings of the Interviews}

The main findings of the study are presented based upon the following themes:

\subsubsection{Advantages of Using ICT in Teaching Reading Skills}

Upon inquiry on whether or not there are advantages in the use of ICT in teaching reading skills, most of the teachers referred to the attractive features of ICT tools. Although Fadhil who was a teacher in a secondary school in Alor Setar did not use ICT in his teaching of reading, he referred to the advantages of using ICT in teaching reading skills. He specifically stated that:

ICT is beneficial in terms of attracting students' attention. Students will be more interested in the lesson when we use ICT. They are more attentive in class and sometimes even a double-period is not enough. In fact, ICT tools are beneficial because they meet the teacher's teaching objectives. 
He also highlighted the potential of ICT being a useful tool in the teaching of reading as he refers to ICT as having the resourcefulness to the teachers. This finding is in agreement with Melor Md Yunus (2007) statement that ICT could be a learning tool in education.

Some of the teachers referred to the advantages of using internet for improving students' reading abilities. They believed that the students can search more about the reading topics in order to fully comprehend the text. For example, Ida from a secondary school in Tawau described her views on how ICT can facilitate students' learning process:

In terms of reading, I think ICT can help the students with the vocabulary and the meaning of the words in the texts they read. For example, when they are reading a certain article online or when they are watching a movie with English subtitles, they can look up the meaning of unknown words in online dictionaries. So they can learn many words from the web.

This response supports the findings by Yuksel \& Tanriverdi (2009) on the effects of watching captioned movie clips on vocabulary development of EFL learners. When the findings of this study are interpreted, it can be argued that watching movie clips helps the participants of the study to develop their vocabulary knowledge, and this would facilitate the reading process.

Huda from Johor Bahru also highlighted the multi-coloured features of PowerPoint software for presenting the reading text. She stated that these features attract the students' attention to be more attentive while the teacher is teaching reading texts. She added that:

ICT tools make the lessons more interesting. For example, through using PowerPoint slides, the students can pinpoint the words, phrases or structures instead of just reading from texts.

In general, ICT allows the teachers to access to a wide range of information in different formats. Computers, softwares, cameras and any range of ICT devices can all make teaching reading skills more effective and more fun for the students. However, the number of activities and resources available to teachers is truly vast, and judgments need to be made about when and more importantly why ICT should be used. Using ICT, students can engage directly with the area of literacy and they can focus more on their learning activities. This had been agreed by most of the interviewed teachers. Chin from a secondary school in Johor Bahru referred to this issue:

ICT devices make the lesson easier for the teachers to teach. For example, they can just show their lesson using the screen which has been provided by the school. The students also benefit from the ICT tools and improve their abilities in learning new materials.

However, in contradiction with other teachers' attitudes, Nabihah from Tawau disagreed with the view of ICT being beneficial in teaching reading skills. She elaborated her point of view when asked whether or not there are advantages in the use of ICT in the teaching of ESL reading. She believed that ICT could be useful in the pre-reading stage whereby both teachers and students can make use of ICT to get reading materials. She further pointed out that:

ICT is not so much useful except for getting reading materials from the web. Without ICT, we have newspapers too. Newspapers can be a useful source of information and a very good reading material. Here in the school, we have ordered 'The Star' newspaper for each class. However, not all students in the class have the chance to read. And sometimes the papers are lost along the way. This doesn't help much in changing their attitude towards reading. They mostly read the entertainment and sports sections only. If they read other sections, it will actually help them a lot.

It seems that Nabihah preferred non-ICT means in making her students read. However, it could be inferred from her comments that even by using authentic materials like the newspaper, the students' reading skills could not be much polished too. Moreover, in Hasnah's feedback, she felt that ICT is not beneficial in terms of teaching reading skills. She stated that "I think it is more beneficial to photocopy worksheets or handouts from the textbooks for reading activities." From this comment, it can be understood that ICT is not seen as an aid in the teaching of reading skills. She still preferred making hard copies of the worksheets or handouts from the students' textbooks.

\subsubsection{Advantages of Using ICT in Teaching Writing Skills}

When the teachers were asked to give their responses on the benefits of using ICT in teaching writing skills, most of them stated that ICT tools can be useful and effective in conducting writing activities. They unanimously believed that the conventional methods of teaching ESL writing make the students bored during the class time. In the same way, Najeeb from Tawau stated that: 
Using ICT can motivate my students to be creative and learn in an enjoyable environment. For example, they can easily write their essays anytime because they can find a lot of information about each topic on the web.

In agreement with Najeeb's opinion, Badariah from a secondary school in Johor Bahru referred to the benefits of surfing the net for the students to improve their writing skills. She added that:

Students can use the Internet to search for the information they may need for writing. For example, if they are going to write about a personality they admire, they can 'google' to find more information about the person they selected.

In the same way, Siti who is from a secondary school in Alor Setar added that she does not use ICT in her classes; however, she referred to the general advantages of ICT usage in the process of education. She specifically stated that:

There are some good points in the use of ICT to teach writing. Students now are so closely linked to ICT. They are using ICT outside school almost every day. When ICT is used, the students can learn more easily. If they can use ICT in the classroom for the purpose of reading and writing, I think the learning process can be more meaningful.

The point on meaningful learning touched by Siti reverberates with the literature whereby Meyer (2002) suggested that ICT is seen to provide a platform for active and meaningful learning to occur.

Moreover, Hasnah responded very positively towards the view of ICT being utilised for the purpose of teaching writing skills. She stressed on how ICT as a teaching tool could help make the lesson more interesting, which in turn could keep the students focused in class. When the teachers can draw the students' attention in the class, the lessons could be carried out more smoothly and when that happens, the students will not be so bored as well. In agreement with Hasnah's opinion, Fetty from a cluster school in Johor Bahru highlighted how the current generation of students are put side by side with ICT. Students, as she has said, are using the ICT tools themselves even out of school. The current twenty-first century students as Sweeny (2010) put, should be treated differently in terms of teachers' methods of teaching. It is suggested that if students are able to use the ICT tools themselves outside the school, it would really benefit them if the ICT tools are integrated in the teaching of reading and writing as well.

From a cluster school in Alor Setar, Zalilah commented on how the current generation of students are different in terms of their creativity and self-discovery skills. She believed that today's students are able to do many things on their own including searching for educational related materials online. She also added the following with an example:

We teachers are not bound to the traditional way of teaching. The students now are different. Students are more creative now; they are able to search for materials on the net themselves. Once I gave my Form 4 students a writing exercise. It was a formal letter. I did not explain to them the format or the content they should include in the letter. I just gave them the topic. After the school holiday, I expected to repeat the lesson but the students had already completed the exercise! I asked them how they did it and they said they just searched the topic in the 'Google'.

Furthermore, Nabihah from Tawau commented on the benefits of using ICT in assisting students of the lower English language proficiencies. She stated that:

With the use of ICT, students seemed to be able to read more model essays which could assist them both in reading and writing processes. Another point emphasized here is about how ICT and the materials on the internet could facilitate students' learning of new lexical items.

In general, in agreement with Labbo \& Kuhn's (2000) findings, it can be highlighted that ICT allows the students to create and share their works. Some softwares allow them to create graphics and multimedia projects so that they can read and do the activities. Moreover, the use of internet allows information sharing through resources such as online research, personal web pages, and e-mail. In fact, electronic references allow students to read various kinds of reading materials and do some research activities.

\subsubsection{Disadvantages of Using ICT in Teaching Reading Skills}

In response to the question on whether or not the teachers see any drawbacks of using ICT in the teaching of reading, most of the interviewed teachers highlighted time and place constraint, internet connection problems, lack of ICT knowledge and insufficient ICT tools as the most important factors preventing teachers to use ICT in teaching reading skills. For example, class control is something that many teachers would need to master, 
especially novices. Therefore, it could be one of the reasons why the teachers did not prefer to use ICT in their teaching of reading and writing skills. Nabihah from Tawau drew our attention to the problem of class control when she said:

When you bring students to the computer labs, it's more difficult to control them. Sometimes you might want them to read a certain article online, but they might be distracted to see other websites. When the students have computers in front of them, they tend to visit other websites and not do the tasks you have assigned for them.

From the same secondary school in Tawau, Nisa also referred to the problem of students' distraction. She believed that ICT brings excitement amongst students but that excitement can affect students' focus of attention inside the classroom. This could further cause destructive noise when the students 'talk more and do less'. She continued that:

When you're always using the books and blackboard in English classes, students are already very used to that method. When you start to use ICT, students will get very excited. So, they might get distracted especially when you get them to be engaged with ICT. I mean, when they get to use the computers and internet themselves. Another thing is that they tend to focus less when they get too excited about something.

Lai from a secondary school in Alor Setar referred to the lackadaisical attitude of the students when they have the freedom to access the internet on their own. She expressed her worries about ICT usage when she said:

I'm afraid of what the students actually learn from the use of ICT. Sometimes you want the students to search for articles on the net but they might browse other inappropriate sites and they end up not reading the appropriate articles. When you ask them to print out one suitable article to show to you, they might just choose the simplest one they can find without actually selecting it.

Moreover, the teachers referred to the poor connectivity of Internet and limited ICT facilities in schools. For example, Goh from Johor Bahru and Hamzah from Tawau respectively explained the drawbacks of using ICT in the teaching of reading:

The poor connectivity of the internet in schools may pose some problems in doing reading and writing activity that needs the internet. Also, the lack of facilities like the LCD projector and individual laptops make extra problems.

The classrooms are not equipped with the ICT tools and I have to bring the students to the computer lab. The capacity of computer labs is insufficient. So how can I cram 30-35 students in a small room with 15-20 chairs? Some of the students have to sit on the floor. And the internet goes on and off, and too slow. Also, there is no technical support.

\subsubsection{Disadvantages of Using ICT in Teaching Writing Skills}

When the teachers were asked about the disadvantages of using ICT in teaching writing skills, most of the teachers referred to the students' use of abbreviations in writing tasks, insufficient time and plagiarizing materials on the net.

Nisa from a secondary school in Tawau highlighted the negative effects of using short forms by the students. She believed that the informal abbreviations ruin the students' writing tasks. She added that:

Speaking from my own experience, I feel that when the students use too much ICT tools, they tend to use a lot of short forms like 'cos' to mean 'because', 'ur' to mean 'your' and many others. They also like to use this SMS language in their essay writing. That's horrible, isn't it?

Moreover, from a secondary school in Johor Bahru, Diyana emphasized that why there is a need to use ICT when non-ICT-based lessons could do the same for her and her students. She also referred to the insufficient time for instruction when ICT is used. She explained that:

I think a lot of time will be wasted when we use ICT. If you only have one period of English, you have only 40 minutes. When you use the computer lab, students need some time to get there. If you're lucky, the LCD is alright and it can detect your laptop. If you're not, you'll spend time with the technical problems. Even if you have double periods, you still do not have enough time to finish what you plan to do with the students. So sometimes I think why do we want to use ICT when we can always do it face-to-face with the students?

Similarly, Fadhil from a secondary school in Alor Setar pointed out that:

You can't be able to give so much input when you want to use ICT. Suppose you assign homework for your students to do. You give the students writing exercises in a blog or ask them to write a post on the blog. You 
cannot expect to get all 100\% students completing the work via the blog. There will be plenty of excuses given by them when they can't complete the task. No internet access will be the main excuse given. While if you give them a task in hard copies like handouts, there is no excuse for them to escape from doing the task.

In the same way, Nisa from Tawau was worried about what the students could actually gain from the writing lessons with the use of ICT. She gave an example of how the students might not be able to relate what they had learnt via ICT to the tasks they attempted. She also inserted her view on the importance of teachers' capabilities in using ICT to ensure that students could follow the lesson well. She specifically stated that:

When you want to use ICT, you need to be good at it. You need to be competent. If not, your lesson will not run smoothly. If teachers can't use ICT competently, it's better for them not to use it. Otherwise, students might not get what you're trying to teach. That's very dangerous. Let's say you use songs to teach them vocabulary before attempting the writing part. After singing and enjoying the song, they might forget the words and just remember the tune of the song.

\subsection{Discussion}

In general, there are many advantages and disadvantages regarding the use of ICT in both the teaching of ESL reading and writing in schools. For the advantages, it is reported that using ICT could help to meet the teachers' teaching objectives as ICT aids the teaching process. This comment resonates with Melor Md Yunus (2007) finding that ICT could be a learning tool in education. Moreover, another finding was that ICT is viewed not as a conventional method, but a new creative method of teaching which the researcher interpreted, as one which could activate active learning among the students (Mullamaa, 2010).

The findings on the advantages also revealed that the use of ICT is beneficial in terms of attracting students' attention. According to one of the interviewed teachers, students were more interested in the lesson when ICT was used. Moreover, the integration of ICT in the teaching of writing was said to encourage learners' independence and self-discovery skills like searching for educational related materials online. This data supports findings by Blachowicz et al. (2009) who found out that the learning technology allowed students to develop independent work habits and to build both their skills and confidence about literacy and about using technology. Students could take responsibility for finding answers to suit their own learning needs (Choi \& Ho, 2002 as cited in Sweeny, 2010).

Another advantage was that ICT could help students improve their vocabulary and enable them to find out the meaning of the words in the texts they read. Many lexical items could also be learnt when they watch any movies with English subtitles. This finding is encouraging as it further confirms the interpretation of findings in the literature whereby Yuksel \& Tanriverdi (2009) who explored the effects of watching captioned movie clip on vocabulary development of EFL learners have argued that viewing the movie clip has helped the participants of the study to develop their vocabulary knowledge, and this would facilitate the reading process.

For the disadvantages, there were only three main findings gained which are the problems on class control, distraction and the improper use of short forms as in the short messaging system (SMS). Apparently, the teachers did not see a lot of disadvantages in the use of ICT in the teaching of reading and writing. They had more to say in terms of the advantages computer technologies have to offer. The three main disadvantages could be overcome without much problem. With stricter ground rules before bringing students to the computer laboratories, teachers would not face so many problems with class control. Moreover, with a central control of the computers, students might not get to visit other irrelevant websites that could distract them from completing the tasks given. As for the tendency to use short forms in writing, students could be given advice and constant reminder so that they will not repeat the mistakes in their writing. As mentioned by Lee (2007), it is important to establish ground rules about the teacher's expectations and the type of language that is acceptable in online environments. This is also to avoid the use of harsh or improper language within the online community. Students need to understand that this school-related communication is different from their social conversations with friends outside of school.

\section{Conclusions and Suggestions}

There were four advantages of using ICT in teaching reading skills as reported by the teachers. Firstly, the use of ICT was said to be beneficial in terms of attracting students' attention. Students were said to be more interested in the lesson when ICT was used. Secondly, it is reported that ICT use could help meet the teacher's teaching objectives as ICT aids the teaching process. The third advantage was that ICT could help students improve their vocabulary and enable them to find out the meaning of the words in the texts they read. This could occur when students read a certain article online, when they check the online dictionary for the meaning of the words which are 
unknown for them. Many lexical items could also be learnt when they watch any movies with English subtitles. Lastly, it is reported that there are advantageous to use ICT in terms of getting suitable reading materials online.

The findings suggested that when ICT was integrated to teach writing, the lesson appeared to be more interesting. Students were reported to be able to relate to what they learn more easily. Adding on, ICT use could help make the learning process more meaningful for ESL learners. Besides, ICT is viewed not as a conventional method, but a new creative method of teaching. Moreover, the integration of ICT in the teaching of writing was said to encourage learners' independence and self-discovery skills like searching for educational related materials online. This happened when students had access to the internet. Besides, the internet enabled students to read good sample essays online which could guide them in their writing process.

It is reported that from the use of ICT in teaching reading skills, teachers found it more difficult to control the class. Students got too excited when ICT was used and this had caused problems to teachers in terms of class control. Besides that, students might be distracted by other elements in the website when they use the internet. Besides the distraction factor, teachers were afraid of the actual content from students' readings on the internet as there were so many articles available and students might not actually read what they are required to.

With regards to the disadvantages of using ICT in teaching writing skills, interviewees reported that students would tend to use the 'SMS language' whereby they use short forms excessively like what they do in the short messaging system (SMS). Also, a lot of time will be wasted when teachers face technical glitches. It was also reported that not much input could be delivered when teachers use ICT and the risk was that students might not get what their teachers were trying to teach.

As a piece of suggestion, teachers' workload in schools should be reduced so as to give them more time to prepare for their lessons. Teaching itself is still the core business of teachers. A lot of time is needed to plan and construct lessons using ICT, especially for teachers who are not competent in using ICT. Hence, other administrative workloads should be reduced to further increase the teachers' use of ICT in their teaching.

Since this research was a pure qualitative study, just in-depth interview was used as the medium of data collection to collect the teachers' attitudes towards the advantages and disadvantages of using ICT tools in teaching ESL reading and writing skills. As a suggestion for future studies, other data collection instruments including survey questionnaire and classroom observations can be utilized to triangulate the obtained data and have more valid and reliable data. Moreover, the same research instruments can be used to investigate the students' perceptions of ICT usage in teaching ESL skills.

\section{References}

Aksal, F. A. (2009). Action plan on communication practices: Roles of tutors at EMU Distance Education Institute to overcome social barriers in constructing knowledge. The Turkish Online Journal of Educational Technology, 8(2), 33-47.

Bialo, E. R., \& Sivin-Kachala, J. (1996). The effectiveness of technology in schools: A summary of recent research. School Library Media Quarterly, 25(1), 51-57.

Blachowicz, C., Bates, A., Berne, J., Bridgman, T., Chaney, J., \& Perney, J. (2009). Technology and at-risk young readers and their classrooms. Reading Psychology, 30(5), 387-411. http://dx.doi.org/10.1080/02702710902733576.

Carlson, S., \& Firpo, J. (2001). Integrating computers into teaching: Findings from a 3-year program in 20 developing countries. In L. R Vandervert, L. V. Shavinina, \& R. A. Cornell (Eds.), Cyber education: The future of distance learning. Larchmont, NY: Mary Ann Liebert, Inc, 85-114.

Choi, C. C., \& Ho, H. (2002). Exploring new literacies in online peer-learning environments. Reading Online, 6(1). $\quad$ Retrieved September $\quad 10, \quad 2012, \quad$ from readingonline.org/newliteracies/lit_index.asp?HREF=choi/index.html

Considine, D., Horton, J., \& Moorman, G. (2009). Teaching and reading the millennial generation through media literacy. Journal of Adolescent and Adult Literacy, 52(6), 471-481.

Fidaoui, D., Bahous, R., \& Bacha, N. N. (2010). CALL in Lebanese elementary ESL writing classrooms. Computer Assisted Language Learning, 23(2), 151-168. http://dx.doi.org/10.1080/09588221003666248

Floyd, R. G., Keith, T. Z., Taub, G. E., \& McGrew, K. S. (2007). Cattell-Horn-Carroll cognitive abilities and their effects on reading decoding skills: $\mathrm{g}$ has indirect effects, more specific abilities have direct effects. School Psychology Quarterly, 22(2), 200-233. http://dx.doi.org/10.1037/1045-3830.22.2.200 
Goldberg, A., Russell, M., \& Cook, A. (2003). The effect of computers on student writing: A metaanalysis of studies from 1992 to 2002. Journal of Technology, Learning, and Assessment, 2(1). Retrieved from http://www.jtla.org

Holder, C. R. (2006). New media and new literacies: Perspectives on change. EDUCAUSE Review, 41(6), 76-77.

Kelly, A., \& Safford, K. (2009). Does teaching complex sentences have to be complicated? Lessons from children's online writing. Journal of Literacy, 43(3), 118-122.

Labbo, L. D., \& Kuhn, M. R. (2000). Weaving chains of affect and cognition: A young child's understanding of CD-ROM talking books. Journal of Literacy Research, 32, 187-210.

Lam, F. S., \& Pennington, M. C. (1995). The computer vs. the pen: A comparative study of word processing in a Hong Kong secondary classroom. Computer-Assisted Language Learning, 8, 75-92.

Lawrence, S. A., McNeal, K., \& Yildiz, M. N. (2009). Summer program helps adolescents merge technology, popular culture, reading, and writing for academic purposes. Journal of Adolescent and Adult Literacy, 52(6), 483-494.

Lee, C. K. (2007). Affordances and text-making practices in online instant messaging. Written Communication, 24(3), 223-249. http://dx.doi.org/10.1177/0741088307303215

Lenhart, A., Arafeh, S., Smith, A., \& Macgill, A. R. (2008). Writing, Technology and Teens. Washington, DC: The Pew Internet \& American Life Project.

Melor Md Yunus. (2007). Malaysian ESL teachers' use of ICT in their classrooms: Expectations and realities. European Association for Computer Assisted Language Learning. ReCALL, 19(1), 79-95.

Meyer, K. (2002). Quality in distance education. San Francisco: Wiley Periodicals.

Ministry of Education Malaysia. (2003). Education Development Plan: 2001-2010.

Mullamaa, K. (2010). ICT in language learning - benefits and methodological implications. International Education Studies, 3(1), 38-44.

Nordin, N., Embi, M. A., \& Yunus, M. M. (2010). Mobile learning framework for lifelong learning. Procedia Social and Behavioral Sciences, 7, 130-138. http://dx.doi.org/10.1016/j.sbspro.2010.10.019

Nordin, N., Hamzah, M. I., Yunus, M. M., \& Embi, M. A. (2010). The mobile learning environment for the in-service school administrators. Procedia - Social and Behavioral Sciences, 7, 671-679. http://dx.doi.org/10.1016/j.sbspro.2010.10.091

Piezon, S. L., \& Donaldson, R. L. (2005). Online groups and social loafing: Understanding student-group interactions. Online Journal of Distance Learning Administration, 8(4).

Salehi, H., \& Salehi, Z. (2011). Washback effect of high-stakes tests on ICT usage: Teachers' perceptions. Australian Journal of Basic and Applied Sciences, 5(12), 1976-1984.

Salehi, H., \& Salehi, Z. (2012). Integration of ICT in language teaching: Challenges and barriers. Proceedings of the 3rd International Conference on e-Education, e-Business, e-Management and e-Learning (IC4E, 2012). IPEDR, 27, 215-219.

Stepp-Greany, J. (2002). Student perceptions on language learning in a technological environment: Implications for the new millennium. Language, Learning and Technology, 6, 165-180.

Strassman, B. K., \& O'Connell, T. (2007). Authoring with video. The Reading Teacher, 61(4), 330-333.

Sweeny, S. M. (2010). Writing for the instant messaging and text messaging generation: Using new literacies to support writing instruction. Journal of Adolescent and Adult Literacy, 54(2), 121-130. http://dx.doi.org/10.1598/JAAL.54.2.4.

Thierer, A. D. (2001). How free computers are filling the "digital divide". Washington, DC: Heritage Foundation.

Ward, J. M. (2004). Blog assisted language earning (BALL): Push button publishing for the pupils. TEFL Web Journal, 3(1), 1-16.

Westera, W., \& Sloep, P. (2001). The future of education in cyberspace. In L. R Vandervert, L. V. Shavinina, \& R. A. Cornell (Eds.), Cyber education: The future of Distance Learning. Larchmont, NY: Mary Ann Liebert, Inc., 115-136. 
Young, S. S. C. (2003). Integrating ICT into second language education in a vocational high school. Journal of Computers Assisted Learning, 19, 447-461. http://dx.doi.org/10.1046/j.0266-4909.2003.00049.x

Yuksel, D., \& Tanriverdi, B. (2009). Effects of watching captioned movie clip on vocabulary development of EFL learners. The Turkish Online Journal of Educational Technology, 8(2), 33-47.

Yunus, M. M., \& Salehi, H. (2012). The effectiveness of Facebook groups on Teaching and Improving Writing: Students' perceptions. Journal of Education and Information Technologies, 1(6), 87-96.

Yunus, M. M., Salehi, H., \& Chenzi, C. (2012). Integrating social networking tools into ESL writing classroom: Strengths and weaknesses. English Language Teaching, 5(8), 42-48. http://dx.doi.org/10.5539/elt.v5n8p42

\section{Copyrights}

Copyright for this article is retained by the author(s), with first publication rights granted to the journal.

This is an open-access article distributed under the terms and conditions of the Creative Commons Attribution license (http://creativecommons.org/licenses/by/3.0/). 